\title{
Foam Stability Study of Dilute Aqueous Nonionic Fluorinated Surfactant Systems
}

\author{
S. C. Sharma ${ }^{1,2 *}$, L. K. Shrestha ${ }^{I}$ and K. Aramaki ${ }^{l}$ \\ 1. Graduate School of Environment and Information Sciences, Yokohama National Univ., Japan. \\ 2. Tokyo University of Science, Faculty of Science and Technology, Chiba 278-8510, Japan. \\ E-mail: surajcsharma@yahoo.com
}

\begin{abstract}
Foaming properties of dilute aqueous nonionic fluorinated surfactants, perfluoroalkyl sulfonamide ethoxylate, $\mathrm{C}_{8} \mathrm{~F}_{17} \mathrm{SO}_{2} \mathrm{~N}\left(\mathrm{C}_{3} \mathrm{H}_{7}\right)\left(\mathrm{CH}_{2} \mathrm{CH}_{2} \mathrm{O}\right)_{n} \mathrm{H}$ (abbreviated as $C_{8} F_{17} E O_{n}, n=10,20$ ) has been studied at $25^{\circ} \mathrm{C}$. Both the surfactants produced a large volume of foams that are stable for several hours to a few days depending upon the surfactant concentration. The foam stability increases with increasing the surfactant concentration within the studied surfactant concentration limit. The $C_{8} F_{17} E O_{10} /$ water system shows higher foam stability than that of the $C_{8} F_{17} E O_{20} /$ water system. The foaming properties of the present systems show good correlation between dynamic surface tension properties and the dilatational surface elasticity.
\end{abstract}

\section{Introduction}

Foams are coarse dispersions of gas in relatively small amounts of liquid generally containing surface-active agents. Pure liquid cannot form stable foams unless a traces amount of surface-active materials are present. The pure liquids allow the entrapped gas to escape very quickly and foams are not stable. For example, when a gas bubble is introduced into a pure liquid, it bursts immediately as soon as the liquid has drained off. Nevertheless, in dilute surfactant solutions, as the air-liquid interface expands and the equilibrium at the interface disturbed then a restoring force is set up, which tries to reestablish the equilibrium. This results elastic film and it is less likely to break.

Foamability is the foam generating power of surfactant solutions and is favored by the ability of the surfactant to attain low surface tension in short time when a new interface is created. Experiments have shown that the increase in foamability appears to parallel the lowering of the dynamic surface tension but not the equilibrium surface tension, which is almost constant in the same concentration range. ${ }^{1}$ A direct relationship between the ability to generate a surface tension difference and foamability was reported for aqueous alcohol solutions by Tuinier et al. ${ }^{2}$

The mechanisms leading to film rupture and thus to foam collapse is still a matter of discussion. However previous investigations had shown that foam undergoes selfdestruction process mainly due to liquid drainage, bubble disproportionation and 
coalescence. Liquid drainage is a natural phenomenon due to gravity and unequal surface pressure in the foam lamellae and at the plateau boarder. As the liquid drains off foam bubbles approach toward each other, and may collapse due to collision unless the film lamellae are very thick. Liquid drainage from the foam lamellae to plateau boarder regions causes both film thinning and an increased surface tension, which decreases the relative amount of bulk liquid between the two interfaces. The resulting surface tension gradient forces the liquid to flow from the lower surface tension region to thinner area. Expansion stresses such as those imposed by gravity or capillary forces are opposed by higher surface tension. As a result, the loss of liquid between the interfaces is balanced by a counter flow of liquid and further thinning is prevented. This process of foam stabilization is termed as Gibbs-Marangoni effect. Besides, dynamic interfacial properties such as dynamic surface tension and dilatational elasticity are considered to have a significant contribution in the formation and stability of the foam. ${ }^{3-6}$ Interfaces with high dilatational elasticity values are rigid against disturbances and therefore, highly elastic interface are considered to have better foam stability. ${ }^{7}$

Hydrocarbon-fuel fires pose a serious threat to life and property, and thus require immediate response. To enable a quick response to hydrocarbon-fuel fires, effective and efficient fire-extinguishing agents are needed to prevent damage and reignition of the fires. Fluorinated surfactants comprise a unique class of chemicals that are utilized in fire-fighting applications. Fire-extinguishing foams are formulated to float on flammable liquids and extinguish flames. The foams form a barrier for vapors to escape and cool a hot surface to prevent reignition. Fluorinated surfactants are also used in aqueous filmforming foaming (AFFF) agents to lower the surface tension of water and form a film on the fuel surface. Fire-extinguishing foams containing mixtures of a cationic, an amphoteric and a nonionic fluorinated surfactant have been claimed to spread rapidly on hydrocarbon surfaces. ${ }^{8}$ Fluorinated surfactants are used in dry fire-extinguishing agents to make the power nonwettable by hydrocarbons. The power floats on the surface of the hydrocarbon and hinders the evaporation of the hydrocarbon. The hazard of reignition is there by eliminated. Moreover, a little information on foaming properties of dilute aqueous nonionic fluorinated surfactant systems is available and hence it demands more attention.

In this context, we aim to study the foaming properties of dilute aqueous solution of two nonionic fluorinated surfactants $\mathrm{C}_{8} \mathrm{~F}_{17} \mathrm{SO}_{2} \mathrm{~N}\left(\mathrm{C}_{3} \mathrm{H}_{7}\right)\left(\mathrm{CH}_{2} \mathrm{CH}_{2} \mathrm{O}\right)_{\mathrm{n}} \mathrm{H}$ (abbreviated as $\mathrm{C}_{8} \mathrm{~F}_{17} \mathrm{EO}_{\mathrm{n}}$ where $\mathrm{n}=10$ and 20 ). We also discuss the dynamic surface tension and surface dilatational elasticity on the foamability and foam stability.

\section{Experimental Methods}

Perfluorosurfactants, $\mathrm{N}$-polyoxyethylene- $\mathrm{N}$-propyl perfluorooctane sulfonamide, $\mathrm{C}_{8} \mathrm{~F}_{17} \mathrm{SO}_{2} \mathrm{~N}\left(\mathrm{C}_{3} \mathrm{H}_{7}\right)\left(\mathrm{C}_{2} \mathrm{H}_{4} \mathrm{O}\right)_{\mathrm{n}} \mathrm{H}$ designated as $\mathrm{C}_{8} \mathrm{~F}_{17} \mathrm{EO}_{\mathrm{n}}(\mathrm{n}=10$ and 20) were obtained from Mitsubishi Materials, Japan. The surfactant $\mathrm{C}_{8} \mathrm{~F}_{17} \mathrm{EO}_{10}$ was purified by placing it 
under vacuum for several days in order to remove volatile components until weight became constant. Millipore water was used in all the experiments.

The $0.1 \%$ and $1 \%$ of $\mathrm{C}_{8} \mathrm{~F}_{17} \mathrm{EO}_{10}$ and $\mathrm{C}_{8} \mathrm{~F}_{17} \mathrm{EO}_{20}$ were prepared in water and taken in clean and dry glass bottles. The samples were stirred for few hours at room temperature. The dynamic surface tension was measured using a BP2 tensiometer (Krüss, Germany). Surface ages of bubbles were measured between $5 \mathrm{~ms}$ to $50 \mathrm{~s}$. Surface dilatational elasticity was measured at $25^{\circ} \mathrm{C}$ by the oscillating air bubble (rising drop) method, using Tracker (I. T. Concept, France). The size of air bubble formed inside the test solution was varied sinusoidally. The variation of the surface area of the bubble and the surface tension was measured from the image analysis of the bubble.

Foam generated method is described elsewhere. ${ }^{9,10}$ The possible mechanical vibration was avoided during foam stability measurement. Maintaining all the measurement conditions identical, effect of surfactant concentrations on the foamability and stability for the surfactant systems were studied at $25^{\circ} \mathrm{C}$.

\section{Results and discussion}

\section{Foam stability}

Figure 1 shows the change of foam value of the fluorinated surfactants in two concentrations as a function of time. The foam stability (dry foams) increases with increasing surfactant concentration as shown in Fig. 1(a). Nevertheless, the foam stability up to $2 \mathrm{hrs}$ is apparently the same in both the concentrations. The foam stability in the first phase (up to about $2 \mathrm{hrs}$ ) is attributed to the drainage of the bulk liquid. The liquid drainage in the liquid foam is inevitable due to gravitational force, the pressure difference between the film lamellae and the plateau boarder. The difference in the drainage rate indicates different foam stability but in the present study found that the same foam stability in the first phase. This indicates that in both the systems the liquid drainage is apparently the same. When the drainage is almost complete, the foam film becomes dry (higher volume fraction of gas compared to the liquid) and the foam stability is influenced by the interfacial dynamics. Similar concentration effect on the foam stability was observed in the $\mathrm{C}_{8} \mathrm{~F}_{17} \mathrm{EO}_{20}$ system also. Consequently, the foam stability is high at higher surfactant concentration. Figure 1 (b) shows the foaming properties for the $\mathrm{C}_{8} \mathrm{~F}_{17} \mathrm{EO}_{10}$ and $\mathrm{C}_{8} \mathrm{~F}_{17} \mathrm{EO}_{20}$ systems at fixed surfactant concentration (1 wt \%). The foam stability is higher in the former system throughout the studied period of time. The higher foam stability in the $\mathrm{C}_{8} \mathrm{~F}_{17} \mathrm{EO}_{10}$ system is attributed to the micellar structure. It is well known that the solution viscosity differs depending on the micellar structure. Spherical

micellar solutions are less viscous compared to the long cylindrical micelles. ${ }^{11}$ The hydrophilic surfactants with large head group generally form spherical micelles, whereas hydrophobic surfactants with smaller head group form cylindrical micelles. In general, the hydrophilic head group size of the $\mathrm{C}_{8} \mathrm{~F}_{17} \mathrm{EO}_{20}$ is nearly double of the $\mathrm{C}_{8} \mathrm{~F}_{17} \mathrm{EO}_{10}$. Therefore, it tends to form less viscous spherical micelles. It has recently found that the $\mathrm{C}_{8} \mathrm{~F}_{17} \mathrm{EO}_{10}$ forms cylindrical micelles in dilute aqueous regime, whereas the $\mathrm{C}_{8} \mathrm{~F}_{17} \mathrm{EO}_{20}$ 
forms spherical micelles. ${ }^{12,13}$ The higher liquid drainage in the $\mathrm{C}_{8} \mathrm{~F}_{17} \mathrm{EO}_{20}$ system is thus due to the formation of spherical micelles. Similarly, the slower drainage rate in the $\mathrm{C}_{8} \mathrm{~F}_{17} \mathrm{EO}_{10}$ system is the contribution of the long cylindrical micelles. Thus, the difference in the foaming properties depending on the surfactant nature can be explained on the basis of the micellar structure.
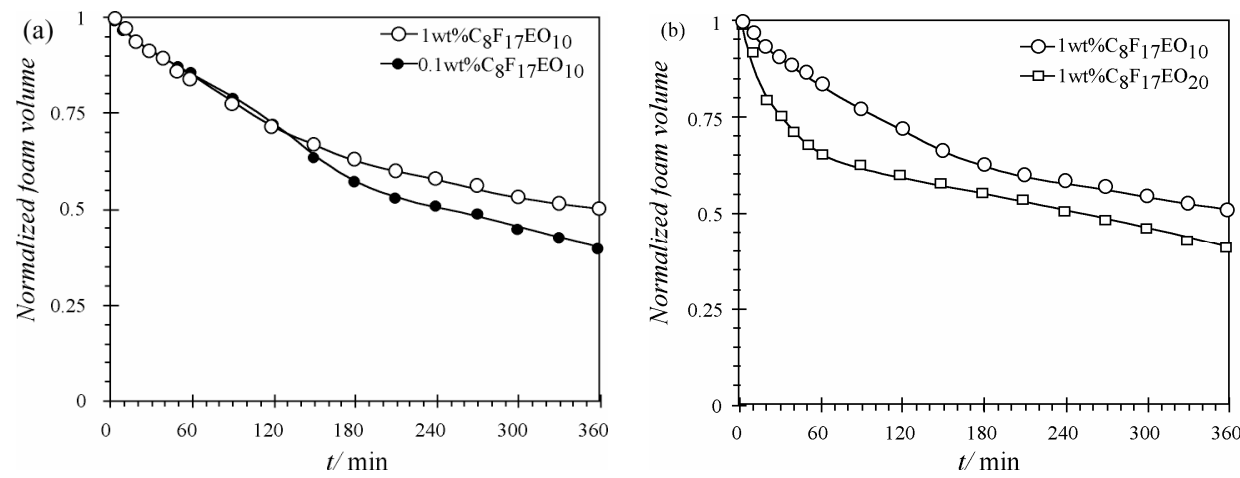

Figure 1: Normalized foam volume versus time for $(a)$ the $C_{8} F_{17} E O_{10}$ system depending on surfactant concentration and (b) the $C_{8} F_{17} E O_{10}$ and $C_{8} F_{17} E O_{20}$ systems at fixed surfactants concentration.

Figure 2 shows the digital images of the foams taken at different interval of time for the $1 \mathrm{wt} \% \mathrm{C}_{8} \mathrm{~F}_{17} \mathrm{EO}_{10}$ system at $25^{\circ} \mathrm{C}$. The system has tendency to produce a large volume of foams (that is, good foamability). Moreover, the foams are stable for several hours. The basic strategy of this study is to compare the foaming properties depending on surfactant nature and concentration. The rate of liquid drainage is very high at the initial stages as seen the volume of liquid drained at the bottom of measuring cylinder (Fig. 2 b). However, after about $2 \mathrm{hrs}$ of foam formation, the drainage is almost complete as confirmed by the constant volume of the liquid drained. The decrease in the net foam volume at the initial stages is therefore attributed to the liquid drainage. At the beginning the foam contains excess amount of liquid so that the foams are wet. As the liquid drainage continued the volume fraction of the liquid in the foam decreased, and hence the foam volume also. When the drainage is almost complete, the foam mainly at the upper part becomes dry (higher volume fraction of gas compared to liquid). The stability of such foam is described by the interfacial surface dilatational elasticity properties, which is described later in this paper. In the dry foams, the film lamellae are very thin and hence increase the possibility of foam coalescence. Two distinct regions of wet and dry foam can be seen in the digital images at $6 \mathrm{hrs}$. The closer view of foam after $24 \mathrm{hrs}$ is shown in Fig. 2(b). Polyhedral type of dry foam film can be seen in this figure. 
(a)

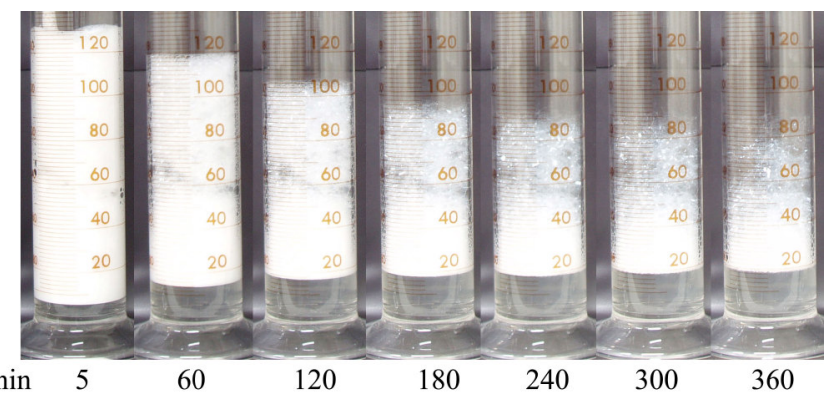

(b)

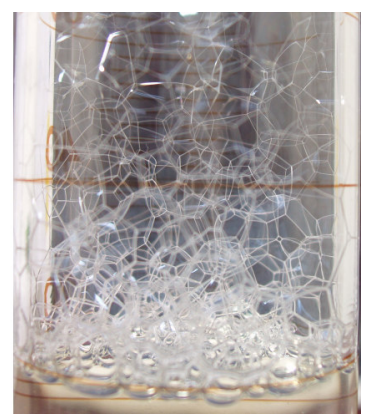

Figure 2: Evolution of foam volume with time for the 1 wt $\% C_{8} F_{17} E O_{10}$ system at $25^{\circ} \mathrm{C}($ a), and the closer view of dry foams after 24 hrs (b).

\section{Dynamic surface tension}

Dynamic surface tensions (DST) of aqueous solutions of $\mathrm{C}_{8} \mathrm{~F}_{17} \mathrm{EO}_{10}$ and $\mathrm{C}_{8} \mathrm{~F}_{17} \mathrm{EO}_{20}$ were measured at 0.1 and $1 \mathrm{wt} \%$ above CMC and the results are shown in Fig.3. When a fresh interface is created surfactant molecules start to migrate at the interface and reduction of surface tension involved several mechanisms ${ }^{14}$ such as (i) diffusional transport, reorientation and adsorption of surfactant molecules, (ii) diffusional transport of the micelles, and (iii) dissociation of micelles. It can be seen from Fig. 3 that the rate of surface tension decay becomes faster as the surfactant concentration increases. Since the systems are above CMC, the micelles act as a reservoir to supply monomeric molecules for the surface according to Kjellin et al. ${ }^{15}$ At a given concentration $(1 \mathrm{wt} \%)$, the aqueous solution of $\mathrm{C}_{8} \mathrm{~F}_{17} \mathrm{EO}_{10}$ shows higher surface tension than that of $\mathrm{C}_{8} \mathrm{~F}_{17} \mathrm{EO}_{20}$ within the time range of measurement, which is very short in comparison to the time required to attain equilibrium value. However, the decay curve of $\mathrm{C}_{8} \mathrm{~F}_{17} \mathrm{EO}_{10}$ indicates that after long time $(\sim 10 \mathrm{~s}), 1 \mathrm{wt} \%$ aqueous solution of $\mathrm{C}_{8} \mathrm{~F}_{17} \mathrm{EO}_{10}$ tends to attain lower surface tension value than that of $1 \mathrm{wt} \%$ of aqueous $\mathrm{C}_{8} \mathrm{~F}_{17} \mathrm{EO}_{20}$. The similar behavior had explained in presence of very stable micelles that slow down the diffusion process. ${ }^{16}$ In general, foamability of the surfactant solution is related to the dynamic surface tension. Even though, the $\mathrm{C}_{8} \mathrm{~F}_{17} \mathrm{EO}_{20}$ system shows faster decay of surface tension but the $\mathrm{C}_{8} \mathrm{~F}_{17} \mathrm{EO}_{10}$ system is more effective in reducing the surface tension at fixed surfactant concentration as a result it is expected to have better foamability. However, a significant difference in the foamability of both surfactant systems can not be observed at the present experimental conditions. 


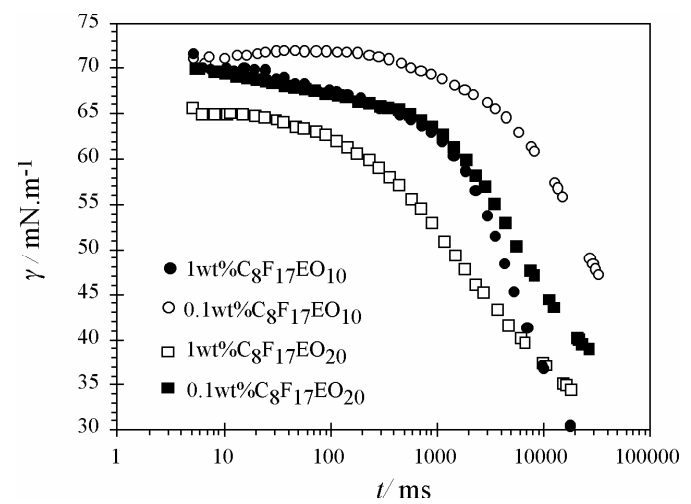

Figure 3: Dynamic surface tension of aqueous solutions of $C_{8} F_{17} E O_{20}$ and $C_{8} F_{17} E O_{10}$ systems at different surfactant concentration at $25^{\circ} \mathrm{C}$.

\section{Surface dilatational rheology}

The interfacial surface dilatational elasticity $\left|E^{*}\right|$ of an air-liquid interface of area, A undergoing a periodic dilatation is given by the equation

$$
\left|E^{*}\right|=\frac{d \gamma}{d \ln A}
$$

Where, $d \gamma$ is the small change in surface tension due to small change in area $d A$. The interfacial elasticity is related to the ability of the perturbed interface to retain the equilibrium tension, which mainly depends on the kinetics of the exchange of the surfactant molecules between the bulk and interface. This kinetics is highly dependent on the dilatational frequency and nature of the surfactant molecules. When the interfacial dilatational frequency is high, the surfactant molecules have no time for bulk-interface exchange and the value of surface tension deviates from the equilibrium value, and consequently the magnitude of $\left|E^{*}\right|$ increases. At very fast dilatational frequency, it has been reported that the elasticity becomes independent of the oscillation frequency. ${ }^{17,18}$ Figure 4 shows the variation of the modulus of surface dilatational elasticity as a function of oscillation frequency for $\mathrm{C}_{8} \mathrm{~F}_{17} \mathrm{EO}_{20}$ and $\mathrm{C}_{8} \mathrm{~F}_{17} \mathrm{EO}_{10}$ aqueous solutions at different concentration at $25^{\circ} \mathrm{C}$. In all measurements, the interface was allowed to attain equilibrium surface tension before inducing sinusoidal deformation.

Increasing the surfactant concentration increases the extent of adsorption of surfactant molecules at the interface. The surface tension will not change appreciably compared to surface area of the interface and hence elasticity decreases. That is why the elasticity value at $1 \mathrm{wt} \%$ is lower than $0.1 \mathrm{wt} \%$ for $\mathrm{C}_{8} \mathrm{~F}_{17} \mathrm{EO}_{20}$ although the difference between elasticity values is narrow. However, the opposite trend of increasing the surface elasticity value with the surfactant concentration is observed in the $\mathrm{C}_{8} \mathrm{~F}_{17} \mathrm{EO}_{10}$ system. This result contradicts the general trend for the variation of elasticity with surfactant concentration. This anomalous behavior is attributed to the different micellar structure in $1 \mathrm{wt} \% \mathrm{C}_{8} \mathrm{~F}_{17} \mathrm{EO}_{10}$ system. From the viscosity measurement, it had found that the viscosity 
of $1 \mathrm{wt} \% \mathrm{C}_{8} \mathrm{~F}_{17} \mathrm{EO}_{10}$ sample was nearly one hundred fifty times higher than that of pure water at $25^{\circ} \mathrm{C}$. This indicates the formation of long entangled micelles and hence the diffusion of monomers from micellar reservoir is slower within time scale of measurement. The correlation between the foam stability and the surface dilatational elasticity is a very complicated field. However, in the present systems, trends in the foam stability of the studied systems seem to be well correlated with the surface dilatational elasticity. The higher elasticity value of the aqueous $\mathrm{C}_{8} \mathrm{~F}_{17} \mathrm{EO}_{10}$ system is reflected in the foaming properties. Due to rigid gas-liquid interface, the foam stability in the $\mathrm{C}_{8} \mathrm{~F}_{17} \mathrm{EO}_{10}$ is higher compared to the $\mathrm{C}_{8} \mathrm{~F}_{17} \mathrm{EO}_{20}$, in which low elasticity values are observed. It had reported that low elasticity makes the interface less rigid and it is easy to collapse. ${ }^{19}$ However, it should be noted that the surface dilatational measurement was done in low frequency range $(0.1-1 \mathrm{~Hz})$ and it is possible that the perturbation of this time scale may not be crucial for the stability of the interface. In fact, it is not clearly known about the time scale of perturbation that determines the stability of air-water interface.

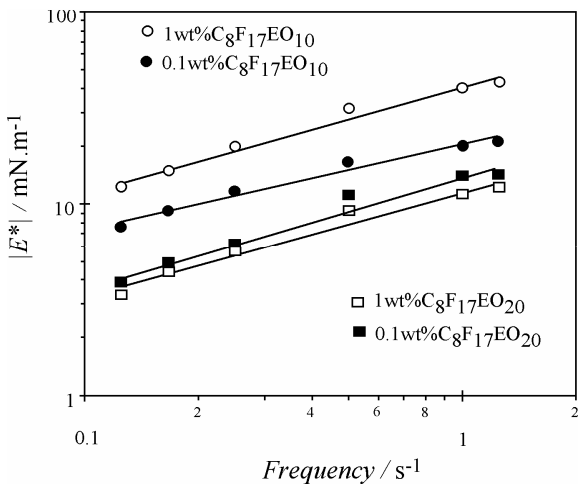

Figure 4: The surface dilatational elasticity versus oscillatory frequency at various concentrations of aqueous solutions of $\mathrm{C}_{8} \mathrm{~F}_{17} \mathrm{EO}_{20}$ and $\mathrm{C}_{8} \mathrm{~F}_{17} \mathrm{EO}_{10}$ at $25^{\circ} \mathrm{C}$.

\section{Conclusions}

The foaming properties of dilute aqueous nonionic fluorinated surfactant systems have investigated at normal room temperature. Depending on the surfactant concentrations and nature, the foaming properties are not same. Both the surfactants $\mathrm{C}_{8} \mathrm{~F}_{17} \mathrm{EO}_{10}$ and $\mathrm{C}_{8} \mathrm{~F}_{17} \mathrm{EO}_{20}$ showed good foamability. The foam stability increased with increasing the surfactant concentration. The better foam stability in the $\mathrm{C}_{8} \mathrm{~F}_{17} \mathrm{EO}_{10}$ system compared to the $\mathrm{C}_{8} \mathrm{~F}_{17} \mathrm{EO}_{20}$ is attributed to the formation of long cylindrical micelles, which increases the viscosity of the solution and hence controls the liquid drainage. The foaming properties of the both surfactant systems show good correlation with dynamic surface tension properties and the dilatational surface elasticity.

\section{Acknowledgements}

This work was partly supported by Core Research for Evolution Science and Technology (CREST) of JST Corporation. S. C. Sharma and L. K. Shrestha are thankful 
to the Ministry of Education, Culture, Sports, Science and Technology (MEXT) of Japan for providing the Monbukagakusho Scholarship.

\section{References}

1. R. J. Pugh, Adv. Colloid Interface Sci., 1996, 64, 67-142.

${ }^{2 .}$ R. Tuinier, C. G. J.Bisperink, C.Van den Berg, A.Prins, J. Colloid Interface Sci., 1996, 179, 327-334.

3. T. Tamura, Y. Kaneko, M. Ohyama, J. Colloid Interface Sci., 1995, 173, 493-499.

${ }^{4}$ C. Stubenrauch, R. Miller, J. Phys. Chem. B., 2004, 108, 6412-6421.

5. Y. H. Kim, K. Koczo, D. T. Wasan, J. Colloid Interface Sci., 1997, 187, 29-44.

${ }^{6 .}$ E. H. Lucassen-Reynders, J. Colloid Interface Sci., 1987, 117, 589-590.

7. D. Beneventi, R. J. Pugh, B. Carre, A. Gandini, J. Colloid Interface Sci, 2003, 268, 221-229.

${ }^{8 .}$ L. Ting, D. T. Wasan, K. Miyano, S. -Q. Xu, J. Colloid Interface Sci., 1984, 102, 248-259.

9. L. K. Shrestha, K. Aramaki, H. Kato, Y. Takase, H. Kunieda, Langmuir, 2006, 22, 8337-8345.

${ }^{10 .}$ L. K. Shrestha, E. Saito, R. G. Shrestha, H. Kato, Y. Takase, K. Aramaki, Colloid and Surf. A. 2007, 293, 262-271.

${ }^{11 .}$ O. Glatter, G. Fritz, H. Lindner, J. B. Popela, R. MIttelbach, R. Strey, S. U.

Egelhaaf, Langmuir, 2000, 16, 8692-8701.

12. D. P. Acharya, S. C. Sharma, C. Rodriguez, K. Aramaki, J. Phys. Chem. B, 2006, 110, 20224-20234.

13. S. C. Sharma, C. Rodriguez, L. K. Shrestha, K. Aramaki, J. Colloid Interface Sci. 2007 (Submitted).

14. B. V. Zhmud, F. Tiberg, J. Kizling, Langmuir, 2000, 16, 2557-2565.

${ }^{15 .}$ U. R. M. Kjellin, J. R. Reimer, P. Hansson, J. Colloid Interface Sci., 2003, 262, 506-515.

16. A. Patist, J. R. Kanicky, P. K. Sukla, D. O. Shah, J. Colloid Interface Sci., 2002, 245, 1-15.

17 . K. -D. Wantke, H. Fruhner, J. Örtegren, Colloids Surf. A, 2003, 221, 185-195.

${ }^{18 .}$ K. D. Danov, D. S. Valkovska, P. A. Kralchevsky, J. Colloid Interface Sci., 2002, 251, 18-25.

${ }^{19 .}$ D. P. Acharya, J. M. Gutiérrez, K. Aramaki, K. I. Aratani, H. Kunieda, J. Colloid Interface Sci., 2005, 291, 236-243. 